\title{
Temporomandibular joint sounds and disc dislocations incidence after orotracheal intubation
}

This article was published in the following Dove Press journal:

Clinical, Cosmetic and Investigational Dentistry

7 December 2009

Number of times this article has been viewed

Estela T Rodrigues'

Iván C Suazo²

Antonio S Guimarães ${ }^{3}$

'Centro de Pós Graduação em Odontologia São Leopoldo Mandic, Campinas, Brasil; ${ }^{2}$ Department of Morphology. Universidad de Talca, Talca, Chile; ${ }^{3}$ Centro de Pós Graduação em Odontologia São Leopoldo Mandic, Campinas, Brasil

Correspondence: Iván Suazo Galdames Department of Morphology, Universidad de Talca, Avenida Lircay s/n Talca, Chile Tel +56 7l 201576 Email isuazo@utalca.cl
Abstract: The aim of this study was to analyze the temporomandibular joint (TMJ) disc displacement and articular sounds incidence after orotracheal intubation. A prospective cohort study was conducted in the Hospital Universitário do Oeste do Paraná (HUOP), in Cascavel, Brazil. 100 patients (aged 14-74 years, mean 44 years), 34 male and 66 female, in need of surgical procedure with orotracheal intubation were evaluated. The anterior disc displacement with reduction incidence and the nonclassifiable sounds incidence by the Research Diagnostic Criteria Axis I was evaluated in all patients after orotracheal intubation. The patients was evaluated one day before and until two days after the procedure. Eight percent present with anterior disc displacement with reduction and $10 \%$ presented nonclassifiable sounds after the orotracheal intubation. There was no correlation of any kind regarding gender related influence in the incidence of disc dislocations $(P=0.2591)$ and TMJ sounds $(P=0.487)$. Although anterior disc dislocations and TMJ sounds after anesthetic with orotracheal intubation presented a low incidence $(8 \%-10 \%)$, it is recommended that the evaluation of TMJ signs and symptoms be done before the anesthetic procedure to take care with susceptible patients manipulation.

Keywords: orotracheal intubation, TMJ sounds, TMJ dislocations, TMJ disorders, disc displacement, surgical procedure

\section{Introduction}

The anterior disc displacement with reduction is one of the temporomandibular disorder (TMD) that produces articular sounds and that can indicate alterations in temporomandibular joint (TMJ). ${ }^{1-3}$ It occurs when the disc is positioned in an abnormal relation to the condyle; in the most cases it is positioned anterior and slightly medial, ${ }^{4}$ it is characterized by the reciprocal clicking, a sound that occurs both during the opening and before the closing movement. ${ }^{5}$ It can be caused by some change in the articular disc, condyle and mandibular fossa relation, or by a muscular incoordination activity. ${ }^{6-8}$

The dental professional usually find articular sounds in their patients because it is the most frequent of all TMD signs and symptoms. ${ }^{9,10}$ Although the TMJ sounds can be generated by different mechanisms, the majority of them are not pathological and can be considered within the normal acceptable variations of normality. ${ }^{11}$ The finding of sounds without the presence of any other TMD sign or symptom is common. ${ }^{4}$

In general, several factors have been identified as initiators of different mechanisms that produce articular sounds. ${ }^{7,12}$ TMJ trauma is the most probable etiologic factor as the causal factor of clicking sounds by TMJ anterior disc displacement with reduction. ${ }^{7,13-16}$ Among these causes are the repetitive microtraumas, oral parafunctions or one unique macrotrauma. ${ }^{3,4,9}$ 
During general anesthesia, TMJ implications must be carefully analyzed. ${ }^{17-19}$ The orotracheal intubation requires a forced open mouth procedure of the unconscious patient by the anesthetic procedure. ${ }^{20}$ Furthermore, the orotracheal intubation is usually a benign procedure, which can cause alterations of the TMJ such as the commencement of articular sounds. ${ }^{18,21-24}$

The objective of this research was to analyze the TMJ disc displacement and articular sounds incidence after orotracheal intubation.

\section{Material and methods}

This research project was submitted to the Ethical Comitee of the São Leopoldo Research Center in Dentistry and it was approved with resolution 196/2006. After explanation of the research details as well as the volunteers' agreement to participate, all participants gave their informed consent.

The incidence of articular sounds and disc displacement with reduction was evaluated in 100 patients (aged 14-74 years, average 44 years), 34 male and 66 female, in need of surgical procedure with orotracheal intubation of Hospital Universitário do Oeste do Paraná (HUOP), in Cascavel, Brazil. Prior to the study the researchers could not present any kind of articular sound in the TMJ palpation examination using a set of diagnostic tools for TMD, namely the Research Diagnostic Criteria for Temporomandibular Disorders (RDC/TMD). These represent amultiaxial approach, evaluating clinical aspects of TMD (Axis I) developed for Dworkin and LeResche. ${ }^{25}$ This evaluation was performed in two instances: one day before the orotracheal intubation procedure and up to two days after it (when the patients were capable of doing free mouth movements). The incidence of disc displacement with reduction and nonclassifiable sounds was verified. The Fischer's exact test was applied to study the relation between gender and incidence (with significance of $5 \%$ and with one degree of freedom).

\section{Results}

An incidence of $8 \%$ of anterior disc displacement with reduction and $10 \%$ of nonclassifiable articular sounds by RDC after orotracheal intubation was observed.

Eight patients developed disc displacement with reduction. Seven were female and one male, but upon statistical analysis it was found that there was no influence of gender on that incidence $(P=0.2591)$.

Ten patients presented nonclassifiable sounds after orotracheal intubation. Eight were female and two were male. Again, after statistical analysis there was no influence of gender on that incidence $(P=0.487)$. Overall, an incidence of $18 \%$ of articular sounds after orotracheal intubation was observed. The incidence and risk ratio results are shown in Tables 1 and 2.

\section{Discussion}

The articular sound is a usual and characteristic sign in patients that present TMD. Several authors was indicated that there are three factors in the origin of the clicking: 1) Predispositioning factors (several systemic conditions); 2) Initiating factors (microtraumas e macrotraumas); 3) Perpetuating factors (emotional behavior). ${ }^{3,4,10}$ The existence of predispositioning factors in the development of clicking sounds, associating them with structural compatibility, parafunction, stress, emotional tension and trauma it should be considered in patients that will be subjected to orotracheal intubation. ${ }^{7}$

In this study the anterior disc dislocations and TMJ sounds after anesthetic with orotracheal intubation presented a low incidence $(8 \%-10 \%)$, several authors have reported similar results. ${ }^{15,26,27}$

Although the TMJ sounds after anesthetic procedure with laringoscopy and orotracheal intubation does not mean negligence, ${ }^{23}$ it is recommended that the evaluation of TMJ signs and symptoms be done before the anesthetic procedure to take care with susceptible patients manipulation.

Patients that submit to orotracheal intubation must also have preoperational exams to verify the presence of preexisting signs of TMD as articular sounds. In case of such an observation, these patients must be notified of this alteration to absolve anesthetic professionals' responsibility for consequences of the procedure.

Table I TMJ disc displacement incidence after orotracheal intubation, related to sex differences, in 100 patients

\begin{tabular}{|c|c|c|c|}
\hline & \multicolumn{3}{|c|}{ TMJ disc displacement } \\
\hline & No & Yes & \\
\hline Female & 59 & 7 & 66 \\
\hline \multirow[t]{2}{*}{ Male } & 33 & 1 & 34 \\
\hline & 92 & 8 & 100 \\
\hline Risk & 0.64 & 0.87 & 0.66 \\
\hline \multicolumn{2}{|c|}{ Point estimate } & \multicolumn{2}{|c|}{ (95\% Conf. Interval) } \\
\hline Risk difference & -0.23 & -0.48 & 0.015 \\
\hline Risk ratio & 0.73 & 0.54 & 0.99 \\
\hline Prev. frac. ex. & 0.26 & 0.007 & 0.45 \\
\hline Prev. frac. pop & 0.24 & & \\
\hline
\end{tabular}

Notes: Fisher's exact test, $P=0.25$; Relative risk reduction $=(I-R R) * 100=27 \%$. Abbreviation: TMJ, temporomandibular joint. 
Table 2 TMJ nonclassificable sounds incidence after orotracheal intubation, related to sex differences, in 100 patients

\begin{tabular}{llll}
\hline & \multicolumn{3}{l}{ TMJ nonclassificable sounds } \\
\cline { 2 - 4 } Female & No & Yes & \\
Male & 58 & 8 & 66 \\
& 32 & 2 & 34 \\
Risk & 90 & 10 & 100 \\
& 0.64 & 0.8 & 0.66 \\
Risk difference & Point estimate & \multicolumn{2}{c}{$(95 \%$ Conf. Interval) } \\
Risk ratio & -0.15 & -0.42 & 0.11 \\
Prev. frac. ex. & 0.80 & 0.57 & 1.13 \\
Prev. frac. pop & 0.19 & -0.13 & 0.42 \\
\hline
\end{tabular}

Notes: Fisher's exact test, $P=0.48$; Relative risk reduction $=(I-R R) * 100=20 \%$.

Abbreviation: TMJ, temporomandibular joint.

In cases where there are no articular sounds as signs or symptoms of TMJ, the patient must be informed of the risk of their initiation due to the orotracheal intubation, as in some cases this procedure is indeed necessary and can not be avoided.

\section{Disclosures}

The authors report no conflicts of interest in this work.

\section{References}

1. Bracco P, Deregibus A, Piscetta R, Giaretta GA. TMJ clicking: a comparison of clinical examination, sonography, and axiography. Cranio. 1997;15:121-126.

2. Watt DM. Temporomandibular joint sounds. J Dent. 1980;8:119-127.

3. Okeson JP. Joint intracapsular disorders: diagnostic and nonsurgical management considerations. Dent Clin North Am. 2007;51:85-103.

4. Carlsson G, Magnusson T, Guimarães A. Tratamento das disfunções temporomandibulares na clínica odontológica. São Paulo, Brazil: Quintessence; 2006.

5. Eriksson L, Westesson PL, Rohlin M. Temporomandibular joint sounds in patients with disc displacement. Int J Oral Surg. 1985;14:428-436.

6. Watt DM, McPhee PM. An analysis of temporomandibular joint sounds. J Dent. 1983;11:346-355.

7. Tenenbaum HC, Freeman BV, Psutka DJ, Baker GI. Temporomandibular disorders: disc displacements. J Orofac Pain. 1999;13:285-290.
8. Spruijt RJ, Hoogstraten J. The research on temporomandibular joint clicking: a methodological review. J Craniomandib Disord. 1991;5: 45-50.

9. Wabeke KB, Hansson TL, Hoogstraten J, van der Kuy P. Temporomandibular joint clicking: a literature overview. J Craniomandib Disord. 1989;3:163-173.

10. Au AR, Klineberg IJ. Isokinetic exercise management of temporomandibular joint clicking in young adults. J Prosthet Dent. 1993;70:33-39.

11. Prinz JF. Physical mechanisms involved in the genesis of temporomandibular joint sounds. J Oral Rehabil. 1998;25:706-714.

12. Solberg WK. Temporomandibular disorders: management of problems associated with inflammation, chronic hypomobility, and deformity. Br Dent J. 1986;160:421-428.

13. Harkins SJ, Marteney JL. Extrinsic trauma: a significant precipitating factor in temporomandibular dysfunction. J Prosthet Dent. 1985;54:271-272.

14. Goddard G. Articular disk displacement of TMJ due to trauma. Cranio. 1993;11:221-223.

15. Lipp M, Daublander M, Ellmauer ST, von Domarus H, Stauber A, Dick W. Changes in temporomandibular joint functions in various general anesthesia procedures. Anaesthesist. 1988;37:366-373.

16. Schwartz HC, Kendrick RW. Internal derangements of the temporomandibular joint: description of clinical syndromes. Oral Surg Oral Med Oral Pathol. 1984;58:24-29.

17. Redick LF. The temporomandibular joint and tracheal intubation. Anesth Analg. 1987;66:675-676.

18. Oofuvong M. Bilateral temporomandibular joint dislocations during induction of anesthesia and orotracheal intubation. J Med Assoc Thai. 2005;88:695-697.

19. Rastogi NK, Vakharia N, Hung OR. Perioperative anterior dislocation of the temporomandibular joint. Anesth Analg. 1997;84:924-926.

20. Avidan A. Dislocation of the temporomandibular joint due to forceful yawning during induction with propofol. J Clin Anesth. 2002;14: 159-160.

21. Agro F, Salvinelli F, Casale M, Antonelli S. Temporomandibular joint assessment in anaesthetic practice. Br J Anaesth. 2003;90:707-708.

22. Sosis M, Lazar S. Jaw dislocation during general anaesthesia. Can J Anaesth. 1987;34:407-408.

23. Worthington $\mathrm{P}$, Cheney FW. Jaw joint dysfunction and endotracheal intubation. Anesth Analg. 1996;83:659.

24. Szmuk P, Ezri T, Warters DR, Katz J. Anesthetic management of a patient with arthrogryposis multiplex congenita and limited mouth opening. J Clin Anesth. 2001;13:59-60.

25. Dworkin SF, LeResche L. Research diagnostic criteria for temporomandibular disorders: review, criteria, examinations and specifications, critique. J Craniomandib Disord. 1992;6:301-355.

26. Taylor RC, Way WL, Hendrixson RA. Temporomandibular joint problems in relation to the administration of general anesthesia. J Oral Surg. 1968;26:327-329.

27. Aiello G, Metcalf I. Anaesthetic implications of temporomandibular joint disease. Can J Anaesth. 1992;39:610-616.
Clinical, Cosmetic and Investigational Dentistry

\section{Publish your work in this journal}

Clinical, Cosmetic and Investigational Dentistry is an international, peer-reviewed, open access, online journal focusing on the latest clinical and experimental research in dentistry with specific emphasis on cosmetic interventions. Innovative developments in dental materials, techniques and devices that improve outcomes

\section{Dovepress}

and patient satisfaction and preference will be highlighted. The manuscript management system is completely online and includes a very quick and fair peer-review system, which is all easy to use. Visit http://www.dovepress.com/testimonials.php to read real quotes from published authors. 